Members of the Working Party contributed about six hours each, including time spent on the ranking exercise and in meetings. Preparatory work by a project officer and manager was time consuming and included the drafting of the framework and indicators, a discussion paper, and preparing and analysing the results of the ranking exercise. Despite efforts to minimise the time spent by the clinical experts, three of the 17 Working Party members did not participate in the ranking exercise.

Delays in developing clinical information systems to support indicators may undermine the processes of developing minimum data sets to monitor the quality and outcomes of patient care. Recently, health information initiatives have been given a fresh impetus by the recommendations of the NSW Health Council, ${ }^{10}$ and the NSW Government's Action Plan for Health. ${ }^{11}$ Consequently, the time between the development of priority sets of indicators and availability of data should be reduced.

We think that the benefits of following this process of developing indicators, if realised, would justify the costs. The process provides an assurance from the data users about what should and could be measured. Therefore, we think that it ensures that resources spent on collecting data are spent giving the best possible information about the quality of services.

\section{ACKNOWLEDGEMENTS}

The authors wish to thank the remaining members of the NSW Melanoma Clinical Indicators Working Party: Professor Bruce Armstrong (Chair), Professor Alan Coates, Ms Sue Collins, Dr Neil Cooney, Dr Kerry Crotty, Professor Stewart Dunn, Dr Afaf Girgis, Professor Peter
Hersey, Dr Robyn Jordan, Professor Bill McCarthy, Dr Scott Menzies, Dr Graham Mann, Dr Bob Sillar, Dr Graeme Stevens.

\section{REFERENCES}

1. Australian Cancer Network. Guidelines for the Management of Cutaneous Melanoma. Sydney: Australian Cancer Society, June 1997.

2. Coates M, Tracey E. Cancer in New South Wales. Incidence and mortality 1998. Sydney: NSW Cancer Council, April 2001.

3. NSW Cancer Expert Working Group. Cancer Control-NSW Goals and Targets. Sydney: NSW Department of Health, August 1995.

4. Williamson M, Lonie C, Colagiuri R et al. A framework for applying a health outcomes approach. NSW Public Health Bulletin 1995; 6: 102-106.

5. Nathan S, Gaffney D. Skin cancer control in New South Wales-Health promotion Strategic Plan 1995-2000. Sydney: NSW Cancer Council and NSW Department of Health, 1995.

6. NSW Cancer Council and NSW Department of Health. Skin cancer control strategic plan 2000-2004. Sydney: NSW Cancer Council and NSW Department of Health, 2000.

7. National Health and Medical Research Council. Clinical Practice Guidelines-The management of cutaneous melanoma. Canberra: NHMRC, 1999.

8. Grimshaw $\mathbf{J}$ et al. Developing and implementing clinical practice guidelines. Quality in Health Care, 1995; 4: 55-64.

9. Quality and Outcomes Monitoring Working Party. A proposed method for identifying performance indicators for cancer services. Sydney: NSW Department of Health, 1997.

10. NSW Health Council. Report of the NSW Health Council. Sydney: NSW Department of Health, March 2000.

11. NSW Department of Health. NSW Government's Action Plan for Health-Bulletin Number 1. Sydney: NSW Department of Health, May 2000. it:

\title{
THE ROLE OF THE NSW PAP TEST REGISTER IN MONITORING THE CERVICAL SCREENING PROCESS IN NSW
}

\section{Sacha Macansh \\ Manager, NSW Pap Test Register \\ NSW Cancer Council}

In 1993, the Steering Group on Quality Assurance in Screening for the Prevention of Cancer of the Cervix recognised that cervical cytology registers were uniquely placed to provide comprehensive information that could be used to monitor and improve the quality of cervical screening. ${ }^{1}$ This article describes the NSW Pap Test Register, and how the data that it collects is used to monitor the performance of the NSW Cervical Screening Program. The register was established in 1996 as a central, comprehensive and confidential database of Pap test and cervical histology results for NSW women. It has a number of important functions including the collation of information that can be used to measure, monitor and improve the cervical screening process.
The Register is managed by the NSW Cancer Council and is an integral part of the NSW Cervical Screening Program. It is jointly funded by the NSW Department of Health and the Commonwealth Department of Health and Aged Care. As part of the NSW Cervical Screening Program, the Register aims to reduce the incidence of and mortality from cervical cancer by increasing participation in and improving the performance of cervical screening. The Register contributes to this aim by providing complete, accurate and timely data which can be used to measure key areas of the Program's performance.

\section{REGISTER DATA}

The Public Health Act 1991 determines that pathology laboratories must inform the NSW Pap Test Register of the results of all cervical cancer tests, Pap tests and cervical histology for NSW women. Demographic data for all 


\section{TABLE 4}

\section{DATA VARIABLES COLLECTED BYTHE NSW PAP TEST REGISTER}

Woman's name and address

Date of birth

Date of the test

Whether the test was for screening or diagnostic purposes

Results of the test

Provider number of the person who performed the test

Name of the laboratory and the laboratory accession

number allocated to the test.

\section{TABLE 5}

\section{CERVICAL SCREENING PATHWAY}

Five inter-related steps:

1. Recruitment of women at risk,

2. Competent taking of Pap tests by health practitioner,

3. Laboratory processing of tests,

4. Notification and explanation of results,

5. Management of women with screen detected abnormalities.

these women, except those who choose not to participate, are forwarded to the Register. During the last two years the rate of non-participation in the Register was 2.2 per cent of all tests. Data variables collected by the Register under the Public Health Act are listed in Table 4.

Currently, 52 laboratories in five states and territories process cervical cancer tests for NSW women. These laboratories are electronically linked to the Register. More than 13,000 Pap test results are received by the Register each week, and more than 95 per cent are received within 15 working days of being reported.

Timely, complete and accurate data are important for all the Register's functions. Validation and quality checks are incorporated at each step of data processing to ensure that the Register's record is complete. To help ensure that the data are accurate, feedback loops return the data to laboratories as screening histories, which assist in reporting current tests and quality assurance activities.

\section{MEASURING THE SCREENING PROCESS}

Register data are used by the NSW Cervical Screening Program to measure its progress towards the goal of reducing the effect of cervical cancer in NSW. However, as the screening process involves a number of steps and different groups of stakeholders, it is important to assess a number of different performance criteria at different stages throughout the process.

Cervical screening can be seen as a pathway of interrelated steps (Table 5). Each step is integral to the performance of the Cervical Screening Program as a whole. Register data are able to be used to measure performance at every step except that of notifying women of their results. However, performance at this step is inferred by the number of women who are lost to follow-up (Table 6). Register data is also used to assess different screening criteria, in particular to provide information in terms of both quantity and quality as illustrated in the 'indicator' column of Table 6 .

Performance measures can be used to monitor progress towards the NSW Cervical Screening Program's goals by using performance standards. Performance standards are preset target values that indicate an expected level of performance. These standards may be established by the Program Manager, the NSW Department of Health or existing professional guidelines such as those of the National Health and Medical Research Council.

Variation in service performance or quality can be identified by calculating measures for the different steps in the screening process and at a range of different levels. This allows the Program to identify the most appropriate areas for improvement and resource allocation. This is

FIGURE 2

BIENNIAL SCREENING RATES BY 5-YEAR AGE GROUPS, NSW, 1998-1999

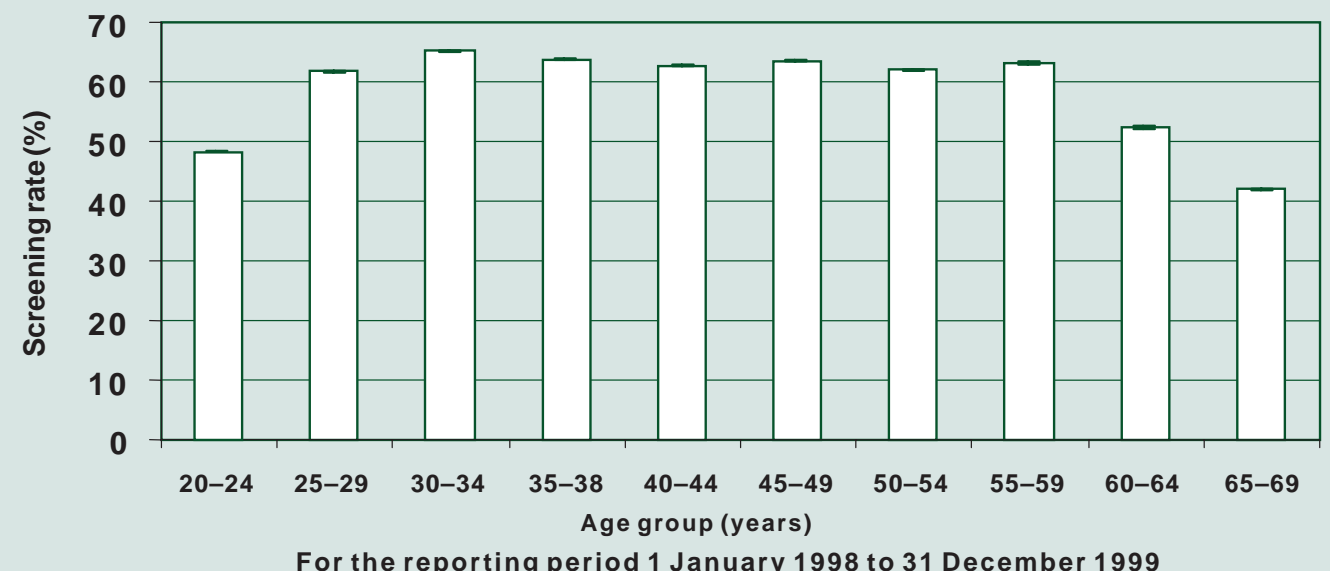

For the reporting period 1 January 1998 to 31 December 1999 


\section{TABLE 6}

MEASURES OF NSW CERVICAL SCREENING PROGRAM PERFORMANCE CALCULATED USING NSW PAPTEST REGISTER DATA COMPAREDTOTHE EXPECTED PERFORMANCE STANDARD

\begin{tabular}{|c|c|c|c|}
\hline Performance Measure & Indicator & $\begin{array}{c}\text { NSW } \\
\text { performance } \\
1999\end{array}$ & $\begin{array}{l}\text { Performance } \\
\text { Standard }\end{array}$ \\
\hline $\begin{array}{l}\text { Percentage of women at risk aged } \\
20 \text { to } 69 \text { years who have been screened } \\
\text { once during a two year period }\end{array}$ & $\begin{array}{l}\text { Recruitment of women at risk } \\
\text { to screening }\end{array}$ & $62.5 \%$ & $65 \%$ * \\
\hline $\begin{array}{l}\text { Percentage of women who screen } \\
\text { more than once during a two } \\
\text { year period }\end{array}$ & $\begin{array}{l}\text { Non-compliance with the } \\
\text { recommended screening interval }\end{array}$ & $39 \% \#$ & $40 \%$ * \\
\hline $\begin{array}{l}\text { Percentage of technically } \\
\text { unsatisfactory Pap tests }\end{array}$ & $\begin{array}{l}\text { Competent test taking by health } \\
\text { practitioner (Quality of test) }\end{array}$ & $2 \%$ & $2 \%$ * \\
\hline $\begin{array}{l}\text { Percentage of technically satisfactory } \\
\text { Pap tests with an endocervical } \\
\text { component }\end{array}$ & $\begin{array}{l}\text { Competent test taking by health } \\
\text { practitioner (Quality, sample adequacy) }\end{array}$ & $88 \%$ & $75 \%$ ** \\
\hline $\begin{array}{l}\text { Proportion of high grade cytology } \\
\text { reports confirmed as high grade } \\
\text { on histology }\end{array}$ & $\begin{array}{l}\text { Laboratory processing and } \\
\text { reporting (Quality) }\end{array}$ & $76 \%$ & $75 \%$ * \\
\hline $\begin{array}{l}\text { Percentage of women with high grade } \\
\text { cytology reports who were not known } \\
\text { to have received follow-up care within } \\
12 \text { months of the index Pap test }\end{array}$ & $\begin{array}{l}\text { Management of women with screen } \\
\text { detected abnormalities in a manner } \\
\text { consistent with NHMRC Guidelines }\end{array}$ & $0.5 \%$ & $\begin{array}{l}\text { Negligible } \\
\text { number * }\end{array}$ \\
\hline \multicolumn{4}{|c|}{$\begin{array}{l}\text { Source of Standards: } \\
\text { * } \\
\text { * } \\
\text { NSW Cervical Screening Program, Strategic plan } 2000-2004,{ }^{2} \\
\# \quad \text { NHMRC Guidelines for the management of women with screen detected abnormalities, }{ }^{3} \\
\text { Index period February } 1998 .\end{array}$} \\
\hline
\end{tabular}

illustrated below for Steps 1 and 3 in the cervical screening pathway.

\section{Step 1: Recruitment of women at risk}

The demographic details of women who are recorded on the Register can be used to monitor and assess activities and projects at both a State and local level. Suburb and postcode variables of a woman's address are used to allocate women to local government and health service areas.

Demographic details also permit the monitoring of target groups: for example, those defined by age (Figure 2). Women aged 50 to 69 years of age are considered a high risk group as they have the lowest screening participation rate but the highest incidence of cancer of the cervix. As a result the recruitment rate of this group of women is specifically monitored. Currently the screening rate for women aged 50 to 69 years in NSW is 59.1 per cent with a target rate of 58 per cent for the 24 month period to June 2001.

\section{Step 3: Laboratory Processing of Results}

Laboratories often collect tests for women who live outside the laboratory's geographic location, so little may be gained from analysing the variation in laboratory performance by the distribution of the woman's area of residence. However, categorising laboratories according to the size of their cytology workload and location may be useful for monitoring laboratory performance. Variation in performance between categories potentially allows education and training activities to be targeted to the staff of laboratories most in need of improvement.

The proportion of high grade intraepithelial Pap test results that are confirmed on histology within six months is considered a measure of laboratory reporting accuracy. ${ }^{4}$ The proportions can be calculated for laboratory

\section{TABLE 7}

PROPORTION OF HIGH GRADE CYTOLOGY REPORTS CONFIRMED AS HIGH GRADE ON HISTOLOGY BY LABORATORY WORKLOAD SIZE AND LOCATION (1 JANUARY-31 DECEMBER 1999)

\begin{tabular}{|c|c|c|c|}
\hline \multicolumn{4}{|c|}{ Laboratory workload size (Pap tests per year) } \\
\hline & $0-5000$ & $5001-20,000$ & Over 20,000 \\
\hline \multicolumn{4}{|c|}{ Laboratory location } \\
\hline Sydney & $69 \%$ & $74 \%$ & $79 \%$ \\
\hline Regional NSW & $63 \%$ & $81 \%$ & No laboratories \\
\hline \multicolumn{4}{|c|}{$\begin{array}{l}\text { Note: The proportion of high grade intraepithial Pap Tests that are confirmed on histology is a measure o } \\
\text { laboratory reporting accuracy. For Pap tests reporting during } 1999 \text { this proportion appears to vary } \\
\text { between laboratories of different workload sizes and laboratories located in different areas. }\end{array}$} \\
\hline
\end{tabular}


categories that are determined by where the laboratory is located and the workload size in terms of numbers of Pap tests reported per year. Table 7 describes how the proportion of high grade intraepithelial Pap tests that are confirmed on histology varies between laboratories of different workload sizes and where the laboratory is located.

To measure the performance of the Cervical Screening Program as a whole, however, cervical cytology registry data must be linked to data from a central cancer registry. Linking these two data sets will allow the screening program to calculate the interval cancer rate. As the interval cancer rate is a measure of cancer incidence in women who are participating in the screening program it reflects screening failure. As a critical assessment of the ability of the Cervical Screening Program to meet its aim of reducing cancer, this is another important measure that uses Register data. The NSW Pap Test Register has been operating for four years and it is now able to calculate this measure for the first time, a process which is under way.

\section{CONCLUSION}

The NSW Pap Test Register, as a registry database, is central to the operation of a cervical screening program. A source of timely, complete and accurate data is vital to monitoring the progress of the screening program towards its aims. The data also provides the Program with measures that can be used to direct program improvement. Performance at different stages of the screening process in terms of quantity and quality as well as at the level of local activities can be assessed using Register data. This information is invaluable to direct the use of finite resources to improve the screening process in the most effective way.

\section{ACKNOWLEDGMENT}

I would like to thank the NSW Department of Health, the NSW Cervical Screening Program, and in particular the staff at the NSW Pap Test Register.

\section{REFERENCES}

1. Commonwealth Department of Health, Housing, Local Government and Community Services. Making the Pap smear better: Report of the Steering Group on Quality Assurance in Screening for the Prevention of Cancer of the Cervix. Canberra: AGPS, 1993

2. NSW Cervical Screening Program, Strategic plan 2000-2004. Sydney: NSW Cervical Screening Program, 2000.

3. National Health and Medical Research Council, Guidelines for the management of women with screen detected abnormalities, Canberra: AGPS, 1994.

4. Commonwealth Department of Health and Family Services, Performance Standards for Australian laboratories reporting cervical cytology, Canberra: AGPS, 1996. Fit $^{2}$

\section{INTERVAL BREAST CANCERS IN NEW SOUTH WALES}

\author{
Richard Taylor, Rajah Supramaniam, Mary Rickard \\ and Jane Estoesta \\ BreastScreen NSW \\ Westmead Hospital
}

This article describes a study that examined the effectiveness of mammographic screening offered to 50-69 year old women in NSW through BreastScreen NSW in 1996.

\section{BACKGROUND}

\section{What is an interval breast cancer ?}

These are cancers that are diagnosed after a woman has had a mammographic screen with a normal result and before her next scheduled screen. The interval cancer rate is an indicator of the effectiveness of mammographic screening programs. It is expressed as a proportion of the number of women screened. A consistently low interval cancer rate is correlated with a significant reduction in mortality from breast cancer in the screened population. ${ }^{1-3}$

\section{Classification of interval cancers}

Interval cancers can be classified by diagnosis: after the first ('prevalent') or a subsequent ('incident') screen, in the first or second year after a previous normal mammogram and by age group and period. Some screening services also classify by a woman's symptomatic status (at the previous mammogram) since those with symptoms, particularly the presence of breast a lump or nipple discharge, have a higher rate of interval cancers even though their previous mammogram showed no sign of cancer. It is preferable to use as few cross classifications as possible because of small numbers and the need for simplicity in data presentation. Interval cancer rates for small populations often must be calculated across a number of years to ensure adequate numbers.

Interval cancers during the first year after a normal mammographic screen are the most significant because they reflect cancers missed by screening. Second year interval cancers are more likely to be cancers which could not have been detected at the previous screen. Second year interval cancers are also more difficult to measure since they merge into cancers diagnosed from early return for biennial screening.

\section{Proportional incidence}

Since the underlying rate of breast cancer incidence varies between populations, interval cancer rates per woman screened are not necessarily directly comparable, especially internationally. For this reason the proportional incidence of interval cancers in the screened population can be used. This is the interval cancer incidence expressed as a proportion of the cancer incidence that would have been expected in the absence of screening in a similar but unscreened population. This statistic can be used to compare outcomes with those of major screening trials. ${ }^{1,2}$ 